\title{
Study on the Evaluation of Higher Vocational College Freshmen's Adaptability Factor Based on AHP
}

\author{
Jian Yong ${ }^{1, a^{*}}$ \\ 'Weihai Vocational College, Shandong, China \\ a1541545319@qq.com
}

Keywords: AHP; Freshmen's adaptability; College students

\begin{abstract}
In recent years, with the national attention to the vocational education, vocational education enrollment scale is getting more and more large, quantity of students in high vocational college is getting more and more, the problems in student management emerge endlessly, the development of students in school is becoming more and more unbalanced, as educators, how to improve students' comprehensive quality, better service students is an important issue in front of us. Freshmen adaptive problem is encountered when we face a new student as the first problem. We research from freshmen adaptive problems in life, culture, studying, professional and growth, to give a reference to educators.
\end{abstract}

\section{Introduction}

In recent years, with the national attention to the vocational education, vocational education enrollment scale is getting more and more large, quantity of students in high vocational college is getting more and more, the problems in student management emerge endlessly, the development of students in school is becoming more and more unbalanced, as educators, how to improve students' comprehensive quality, better service students is an important issue in front of us. Freshmen adaptive problem is encountered when we face new students as the first problem. We research from freshmen adaptive problems in life, culture, studying, professional and growth, to give a reference to educators.

\section{Establish Frame System of Higher Vocational College Freshmen Adaptive Factor}

The principle of Higher Vocational College Freshmen's adaptability factor evaluation establishment: According to the basic requirements of evaluation methods, according to the principles of servicing student, servicing society, improving school quality, we establish frame system of Higher Vocational College Freshmen adaptive factor from the five aspects in life, culture, studying, professional, growth and other factors. See Fig. 1. 


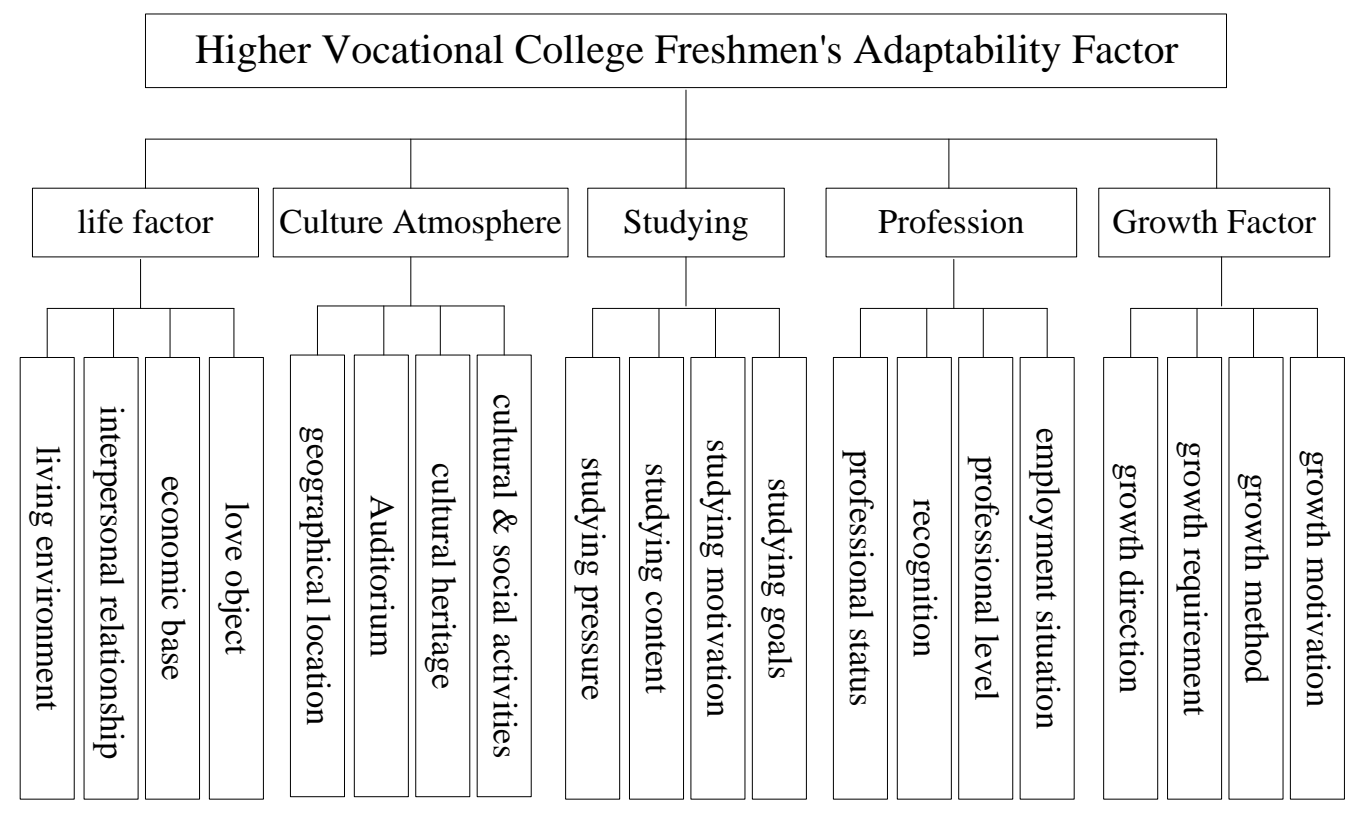

Figure 1. Higher Vocational College Freshmen's Adaptability Factor

At present, higher vocational college freshmen's adaptability factors include life factors, culture factors, studying factors, profession and growth.

Life factor: living environment, interpersonal relationship, economic base, love object

Culture atmosphere: geographical location, auditorium, cultural heritage, cultural and social activities.

Studying: studying pressure, studying content, studying motivation and studying goals.

Profession: professional status, recognition, professional level, employment situation.

Growth factor: growth direction, growth requirement, growth method, growth motivation.

\section{List Paired Comparison Matrix}

List paired comparison matrix on five aspects:

$$
\left[\begin{array}{ccccc}
1 & 2 & 4 & 5 & 7 \\
1 / 2 & 1 & 2 & 3 & 4 \\
1 / 3 & 1 / 2 & 1 & 2 & 3 \\
1 / 5 & 1 / 3 & 1 / 2 & 1 & 2 \\
1 / 7 & 1 / 4 & 1 / 3 & 1 / 2 & 1
\end{array}\right]
$$

$\mathrm{W}=(0.4666,0.2485,0.1427,0.0880,0.0543)$

$$
\lambda_{\text {max }}=5.0475, \mathrm{CI}=0.01188, \mathrm{CR}=0.0106<0.1
$$

Calculate the result and test the consistency to get correct result.

List paired comparison matrix on life factors:

$\left[\begin{array}{cccc}1 & 3 & 4 & 5 \\ 1 / 3 & 1 & 3 & 4 \\ 1 / 4 & 1 / 3 & 1 & 3 \\ 1 / 5 & 1 / 4 & 1 / 3 & 1\end{array}\right]$


$\mathrm{W}=(0.5287,0.2687,0.1343,0.0683)$

$\lambda_{\text {max }}=4.1807, \mathrm{CI}=0.0602, \mathrm{CR}=0.0669<0.1$

Calculate the result and test the consistency to get correct result.

List paired comparison matrix on culture atmosphere:

$\left[\begin{array}{cccc}1 & 2 & 3 & 4 \\ 1 / 2 & 1 & 2 & 3 \\ 1 / 3 & 1 / 2 & 1 & 2 \\ 1 / 4 & 1 / 3 & 1 / 2 & 1\end{array}\right]$

$\mathrm{W}=(0.4668,0.2776,0.1603,0.0953)$

$\lambda_{\text {max }}=4.0310, \mathrm{CI}=0.0103, \mathrm{CR}=0.0115<0.1$

Calculate the result and test the consistency to get correct result.

List paired comparison matrix on studying:

$\left[\begin{array}{cccc}1 & 2 & 3 & 4 \\ 1 / 2 & 1 & 2 & 3 \\ 1 / 3 & 1 / 2 & 1 & 2 \\ 1 / 4 & 1 / 3 & 1 / 2 & 1\end{array}\right]$

$\mathrm{W}=(0.4765,0.2879,0.1547,0.0810)$

$\lambda_{\max }=4.0211, \mathrm{CI}=0.0070, \mathrm{CR}=0.0078<0.1$

Calculate the result and test the consistency to get correct result. list paired comparison matrix on profession:

$$
\begin{aligned}
& {\left[\begin{array}{cccc}
1 & 2 & 3 & 4 \\
1 / 2 & 1 & 2 & 4 \\
1 / 3 & 1 / 2 & 1 & 2 \\
1 / 4 & 1 / 4 & 1 / 2 & 1
\end{array}\right]} \\
& \mathrm{W}=(0.4603,0.2941,0.1580,0.0875) \\
& \lambda_{\max }=4.0457, \quad \mathrm{CI}=0.0152, \mathrm{CR}=0.0169<0.1
\end{aligned}
$$

Calculate the result and test the consistency to get correct result. list paired comparison matrix on growth factors:

$\left[\begin{array}{cccc}1 & 2 & 3 & 5 \\ 1 / 2 & 1 & 2 & 3 \\ 1 / 3 & 1 / 2 & 1 & 2 \\ 1 / 5 & 1 / 3 & 1 / 2 & 1\end{array}\right]$


$\mathrm{W}=(0.4832,0.2717,0.1569,0.0882)$

$\lambda_{\text {max }}=4.0145, \mathrm{CI}=0.0048, \mathrm{CR}=0.0054<0.1$

Calculate the result and test the consistency to get correct result.

\section{Conclusion}

Higher Vocational College Freshmen's adaptability factor index evaluation conclusion:

From the above analysis we can draw the following conclusions: in the five aspects of Higher Vocational College Freshmen's adaptability factors including life factor culture atmosphere, studying, profession and growth, the life factor is the most important. Having a stable life, students can have good mood to study in the new environment; in culture, the geographical position is to bear the brunt, because a city's cultural atmosphere of students have life-long effects; in learning, the size of the learning pressure will affect ascension space in other aspects; in the professional, professional status is the most important; in the growth, direction of growth determines the direction of the development of students.

\section{References}

[1] Discretion and bias in performance evaluation: the impact of diversity and subjectivity Volume [J]:30, Issue: 1, January, 2005, pp.67-78

[2] http://the qualityportal.com/q_ahp.htm. Retrieved 2007-08- 21.

[3] European Management Journal Volume [J]:21, Issue: 3, June, 2003. pp323-337 